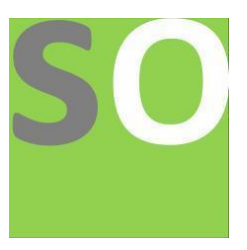

Article title: Designing Pathology Curriculum Through Guided Enquiry/Mixed Modalities Case-Based Learning at Faculty of Medicine, Helwan University.

Authors: Hebat Allah Amin[1], Mohamed Alaaeldin Abdulmonem[2], Omar Gamal Goda[3], Mohamed Hany K. Shehata[4] Affiliations: Helwan University, Faculty of Medicine[1], Arabian Gulf University, Bahrain; Helwan University, Faculty of Medicine[2]

Orcid ids: 0000-0003-3311-4840[1], 0000-0002-7603-1052[2], 0000-0002-0164-5017[3], 0000-0001-7069-9329[4] Contact e-mail: hebatallahahmedamin@gmail.com

License information: This work has been published open access under Creative Commons Attribution License http://creativecommons.org/licenses/by/4.0/, which permits unrestricted use, distribution, and reproduction in any medium, provided the original work is properly cited. Conditions, terms of use and publishing policy can be found at https://www.scienceopen.com/.

Preprint statement: This article is a preprint and has not been peer-reviewed, under consideration and submitted to ScienceOpen Preprints for open peer review.

Funder: None

DOI: 10.14293/S2199-1006.1.SOR-.PPZFS5T.v1

Preprint first posted online: 20 June 2020

Keywords: Case-based learning, Enquiry-based learning, Problem-based learning, Mixed modalities, Peer-assisted learning, Integrated modular curriculum 


\section{Designing Pathology Curriculum Through Guided Enquiry/Mixed Modalities Case-Based Learning at Faculty of Medicine, Helwan University}

\section{Abstract:}

Background: Implementing case-based learning (CBL) in the Integrated Modular Curriculum has proved a great efficiency in teaching medical students. We aim to develop and validate a customized model of CBL to integrate disciplines while meeting the requirements of our national academic reference standards. Phase I medical students' reflection is presented.

Methods: In this retrospective cross-sectional study, we present our experience in introducing CBL in a hybrid mixed model of teaching the pathology course to phase I, first batch (2016-2022) students. The data are collected from feedback questionnaires, the CBL implemented in the teaching of the pathology course is compared to the other implemented methods (didactic lectures, students' presentations, PBL, and skills'labs), in the integrated modules. Also, a focus group has been conducted to receive the students' reflection and suggestions for improvement.

Results: Students' satisfaction with CBL was the highest among all the teaching methods of the modules and other learning modalities with a mean of $4.77 \pm 0.46$. Results were statistically significant $(<0.001)$.

Conclusion: Most of the students declared that the customized CBL model is a convenient tool to be used in the Integrated Modular Curricula. Satisfaction is superior to that of didactic lectures and even other interactive teaching methods.

\section{Introduction:}

Dr. James Lorrain Smith in 1912 was the first to introduce CBL in teaching pathology at the University of Edinburgh (Mclean 2016). Teaching medical students the fundamentals of the basic sciences in the context of clinical cases connect the concepts with practice, thus enhancing long-term retention and deeper understanding. Using differentials of clinical presentations ensures a deep understanding of the basic scientific concepts that will help the students elaborate on that knowledge as they progress into clinical education (National Research Council 2000).

The implementation of case-based learning in the Integrated Modular Curricula is supported by modern medical educational theories and models of integration (Brauer \& Ferguson 2015), including the renowned adult learning theory (Knowles 1980). According to Ambrose et al. 2010, the learners more effectively analyze information by linking knowledge to practice.

The "ICE" transformative model -Ideas/Connections/Extension- also supports this practice. Students attain foundational concepts (ideas), then incorporate them with other concepts (connections) to develop a fundamental conceptual framework. Finally, they apply these integrated concepts to real-life examples (extensions) in a non-linear, non-hierarchial fashion (Fostaty-Young \& Wilson 2000).

According to the Egyptian National Qualification Framework (NQF) descriptors, our medical school students should exhibit the ability to apply the integrated professional knowledge within inter-related domains, use the analytical critical thinking to establish multi-dimensional correlations, and manage the processes in familiar and less familiar contexts. All these competencies could be achieved in a safe environment by the proper application of the CBL (NAQAAE /NARS 2017).

Although CBL is implemented worldwide and the reported studies on it are global, Africa has only $1 \%$ of these studies (Mclean 2016). 
In Egypt, we are facing a great challenge with undergraduate medical education to switch from the traditional fragmented curricula to well-tailored integrated curricula allowing the proper delivery of knowledge, skills, and attitudes.

Our mission in the newly opened Faculty of Medicine, Helwan University (FMHU) is to adopt a "Clinical Presentation Curriculum" in an Integrated Modular Curriculum context.

As there is no absolute definition of case-based learning (CBL) or a specified defined method of delivery (Thistlewaite et al 2012), we would like to present our experience on the methods of adopting the CBL in our pathology curriculum and how it was tailored to meet our personalized learners' needs and overcome the obstacles we have encountered.

\section{Methods:}

\section{I- Design:}

A retrospective, cross-sectional, comparative study on the First Batch (2016-2022), phase I medical students at the Pathology Department, FMHU is presented. The study is based on the students' perception of the teaching methods and courses' structure during phase I modules. Ethical approval has been obtained from FMHU-REC (serial: 16/2019).

The Faculty follows an Integrated Modular Curriculum of credit points approved by the Supreme Council of Universities (SCU) of Egypt. The number of students is 134 students.

After the introductory modules to the basic sciences, students of the selected batch go through integrated modules where 16 (academic and clinical subjects) are represented. The included modules in the study are:

1. Basic neuroscience.

2. Gastrointestinal tract.

3. Respiratory.

4. Cardiovascular.

5. Haematology and Endocrinology.

6. Reproduction.

The pathology course is designed to be the core of integration within the modules as it links the basic concepts and disciplines with the clinical presentations. The CBL is has been designed to be the cornerstone in the teaching process. It has been delivered in a hybrid/mixed modality so that a customized model fitting the needs of our students is achieved. Integration between different departments, especially the clinical ones is sought whenever possible, in the didactic lectures, logbook design, and the CBL.

The average weight of pathology/all disciplines is $12.5 \%$. The average number of case scenarios per module is 50 cases.

We have obtained feedback from students on the modules through two surveys on a 5-point Likert scale (one for the pathology curriculum with the implemented mixed CBL modality and the other for the other implemented methods in the modules. Then, we compared CBL implementation with the other implemented interactive activities and traditional teaching methods.

\section{II- Method of delivery:}

- Retroactive upload of the e-portfolio addressing the learning objectives, references and the schedule of the module is done. The used platform is https://www.pathbrite.com.

- The pathology instructor conducts one CBL session following each didactic lecture. The number of lectures and CBL sessions per week varies from one to two according to the relative weight of the pathology in the module. 
- The lectures and CBL files are made available online at least 24-48 hours before the teaching sessions. Extra material including relevant videos, tutorials, mind maps and picture galleries are also made available in advance.

- The students are encouraged to try to solve the cases, either solely or in teams before their discussion on the campus.

- The objectives of the topics are covered by a lecture, followed by a CBL session where the cases are well-tailored to cover all the objectives. They are structured as single best answer MCQs.

- Cases are discussed in the lecture hall (large group). At the beginning of each CBL session, a mind map of the topic discussed is presented on a whiteboard.

- Any student could be randomly selected to present the case. Then each case is openly discussed with the whole class at three levels as described in the following paragraphs.

Firstly, the stem (case scenario):

- The key points of all relevant data in the stem (history, symptoms, signs, investigations, etc.) are highlighted.

- Any investigational, interventional or surgical procedures (e.g. gFOBT, CT scan, MRI, PR examination, FNAC, MRM, etc.) are depicted for full understanding and interaction.

- After that, the instructor and the students discuss together what the most likely diagnosis of the scenario is and what the possible differentials and the required investigations of such a case could be.

- Then comes the critical thinking; where students are asked to invent parallel scenarios for this case presentation according to what they have been taught in the didactic lecture.

\section{Secondly, the lead:}

It can be a likely diagnosis, possible etiology, possible clinical feature, gross or microscopic features, possible complications, or required investigations. The students are again asked to suggest other alternatives for the question.

Thirdly, options and key:

- Every option is discussed separately whether it is most likely, less likely, least likely or completely rejected and the reason for this.

- Thus the single best answer (key) is reached.

- Students are allowed to freely criticize the structure of the case scenario, lead-in, or options. If criticism is reasonable and agreed upon, the instructor -Amin- responds and changes it.

- Finally, we discuss alternative options for the key.

An example of the process is presented in appendix 1.

\section{III- Surveys and students' reflection:}

First survey: Questions on the pathology course:

Six MCQ questions, 5-tired, are used in the first survey on the feedback on the pathology course (table 1), in addition to a seventh text question for free reflection.

Second survey: Questions on other implemented methods in phase I integrated modules as a whole:

Another similar survey on other implemented methods (CBL, didactic lectures, PBL, Students' presentations, and skill labs) is used for comparative analysis. 
Taking into consideration that adult learning is learner-centred, and as partners in the educational process, a focus group that included 22 students has been conducted (a WhatsApp group) to reflect the students' experience.

\section{IV- $\quad$ Statistical methods:}

Data analysis is performed using the statistical package SPSS version 25 . We selected the parametric analysis as we find it more informative. The mean of each question is represented with the standard deviation for quantitative variables. Relative frequencies of responses are presented for categorical variables. Comparisons between groups are performed using analysis of variance (ANOVA) with multiple comparisons post- hoc Tukey test for comparing the responses between each 2 teaching modalities (Chan, 2003). $\mathrm{P}$-values $<0.05$ are considered as statistically significant.

\section{Results:}

Table 1 and Figure 1: Student response to pathology methods (hybrid/mixed)

128 students out of $134(95.5 \%)$ have responded to the online survey on pathology

feedback. The means for the pathology module questionnaire are $\mathrm{Q} 1=4.63 \pm 0.69$,

$\mathrm{Q} 2=4.69 \pm 0.51, \mathrm{Q} 3$ on the $\mathrm{CBL}=4.77 \pm 0.46, \mathrm{Q} 4=4.51 \pm 0.58, \mathrm{Q} 5=4.30 \pm 0.78$, and $\mathrm{Q} 6=4.46 \pm 0.72$.

The students' satisfaction with CBL showed the highest level among all the components of the pathology methods in the first survey with a mean of $4.77 \pm 0.46$.

The least satisfaction level was that of the assignments with a mean of $4.30 \pm 0.78$.

P-value is statistically significant for each question $(<0.001)$.

AS regards the post- hoc pairwise comparisons between each question and others, they are only statistically significant p-value $(<0.001)$ between Q5 and Q1, Q5 and Q2, and Q5 and Q3. Other correlations are statistically insignificant with p-value $>0.05$.

Table 1: Frequency (cross), Mean and standard deviation, $n=128$

\begin{tabular}{|l|c|c|c|c|c|c|c|}
\hline \multicolumn{1}{|c|}{ Answer Choices } & Excellent & V.good & Good & Fair & Poor & Mean & SD \\
\hline $\begin{array}{l}\text { Q1 Overall, how would you rate the } \\
\text { pathology courses? }\end{array}$ & $71.09 \%$ & $24.22 \%$ & $2.34 \%$ & $1.56 \%$ & $0.78 \%$ & 4.63 & 0.69 \\
\hline $\begin{array}{l}\text { Q2 } \\
\text { How much help was applying the E- } \\
\text { learning modality and the online activities } \\
\text { in the modules? }\end{array}$ & $71.09 \%$ & $26.56 \%$ & $2.34 \%$ & $0.00 \%$ & $0.00 \%$ & 4.69 & 0.51 \\
\hline $\begin{array}{l}\text { Q3 } \\
\text { How much convenient was the } \\
\text { implementation of the CBL to achieve the } \\
\text { learning outcomes? }\end{array}$ & $78.13 \%$ & $20.31 \%$ & $1.56 \%$ & $0.00 \%$ & $0.00 \%$ & 4.77 & 0.46 \\
\hline $\begin{array}{l}\text { Q4 } \\
\text { How useful was the courses' material? }\end{array}$ & $54.69 \%$ & $41.41 \%$ & $3.91 \%$ & $0.00 \%$ & $0.00 \%$ & 4.51 & 0.58 \\
\hline $\begin{array}{l}\text { Q5 } \\
\text { How helpful were the CBL assignments to } \\
\text { your understanding of the material? }\end{array}$ & $46.88 \%$ & $38.28 \%$ & $12.50 \%$ & $2.34 \%$ & $0.00 \%$ & 4.30 & 0.78 \\
\hline $\begin{array}{l}\text { Q6 } \\
\text { How well do the supplied educational } \\
\text { materials meet the various teaching and } \\
\text { learning styles? }\end{array}$ & $59.38 \%$ & $27.34 \%$ & $13.28 \%$ & $0.00 \%$ & $0.00 \%$ & 4.46 & 0.72 \\
\hline P val < 0.001 & & & & & & & \\
\hline
\end{tabular}

$\mathrm{P}$ value $<0.001$ 


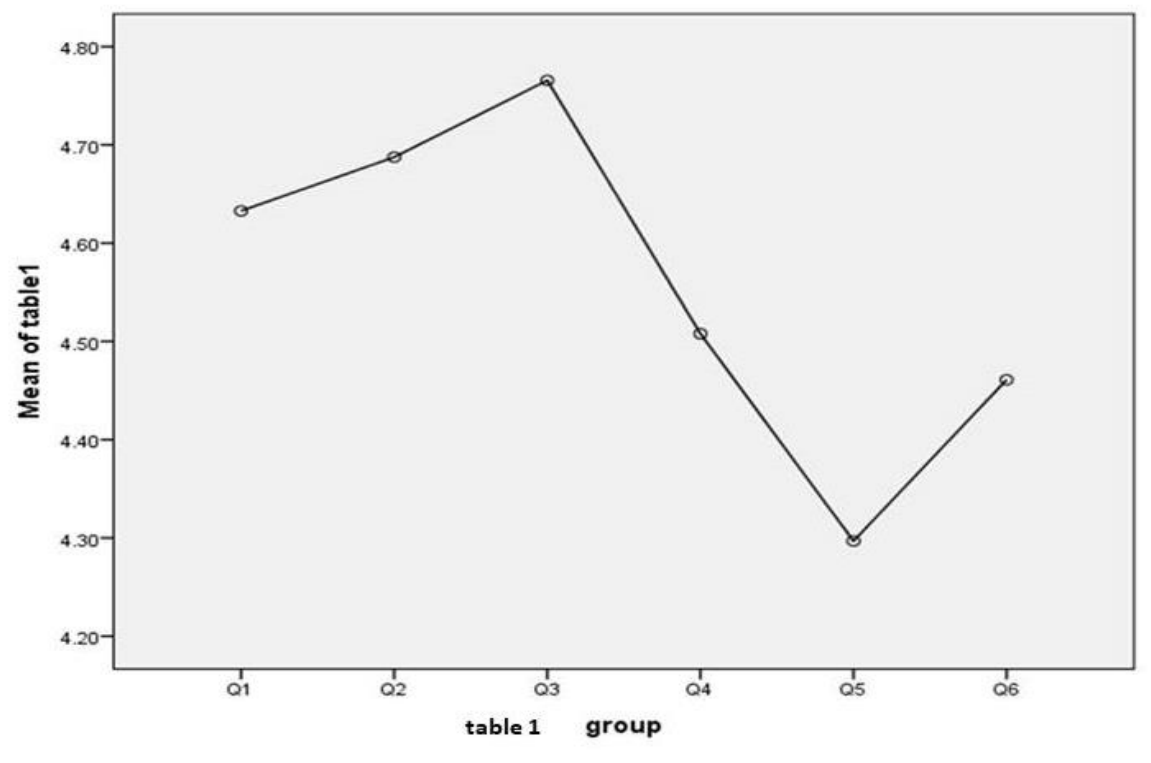

Fig 1 First batch feedback on the pathology courses (Means Plots)

Table 2 and Figure 2: Student response to other implemented modalities in the integrated modules

Seventy-six students out of $134(56.7 \%)$ have responded to the second online survey designed for the other implemented methods in the modules. The means for students satisfaction regarding the other implemented modalities in the module are Q3a on the $\mathrm{CBL}=4.77 \pm 0.46, \mathrm{Q} 3 \mathrm{~b}$ on the didactic lectures $=2.84 \pm 0.95, \mathrm{Q} 3 \mathrm{c}$ on the $\mathrm{PBL}=3.08 \pm 1.19, \mathrm{Q} 3 \mathrm{~d}$ on the $\mathrm{PAL}=1.87 \pm 1.01, \mathrm{Q} 3 \mathrm{e}$ on the skills labs $=3.97 \pm 0.88$.

Peer-Assisted Learning (PAL) (students' presentations) showed the least level of satisfaction with a mean of $1.87 \pm 1.01$.

$\mathrm{P}$-value is statistically significant for each question $(<0.001)$.

Post-Hoc pairwise comparisons between each teaching modality and the other yield statistically significant p-values $(<0.001)$, except for the comparison between the Q3b and Q3c (lectures and PBL) p-value (0.468).

Table 2: Frequency (cross), Mean and standard deviation, $n=76$

\begin{tabular}{|l|c|c|c|c|c|c|c|}
\hline \multicolumn{1}{|c|}{ Answer Choices } & Excellent & V. good & Good & Fair & Poor & Mean & SD \\
\hline $\begin{array}{l}\text { Q 3a } \\
\text { How much convenient was the } \\
\text { implementation of the CBL to achieve } \\
\text { the learning outcomes? }\end{array}$ & $78.13 \%$ & $20.31 \%$ & $1.56 \%$ & $0.00 \%$ & $0.00 \%$ & 4.77 & 0.46 \\
\hline $\begin{array}{l}\text { Q 3b } \\
\text { How much convenient was the } \\
\text { implementation of the didactic } \\
\text { lectures to achieve the learning } \\
\text { outcomes? }\end{array}$ & $5.26 \%$ & $15.79 \%$ & $43.42 \%$ & $28.95 \%$ & $6.58 \%$ & 2.84 & 0.95 \\
\hline $\begin{array}{l}\text { Q 3c } \\
\text { How much convenient was the } \\
\text { implementation of the PBL to achieve } \\
\text { the learning outcomes? }\end{array}$ & $9.21 \%$ & $32.89 \%$ & $27.63 \%$ & $17.11 \%$ & $13.16 \%$ & 3.08 & 1.19 \\
\hline $\begin{array}{l}\text { Q 3d d } \\
\text { How much convenient was the } \\
\text { implementation of the students } \\
\text { presentation to achieve the learning } \\
\text { outcomes? }\end{array}$ & $1.32 \%$ & $7.89 \%$ & $13.16 \%$ & $31.58 \%$ & $46.05 \%$ & 1.87 & 1.01 \\
\hline
\end{tabular}




\begin{tabular}{|l|l|l|l|l|l|l|l|}
\hline $\begin{array}{l}\text { Q3e } \\
\text { How much convenient was the } \\
\text { implementation of the skill labs to } \\
\text { achieve the learning outcomes? }\end{array}$ & $28.95 \%$ & $46.05 \%$ & $19.74 \%$ & $3.95 \%$ & $1.32 \%$ & 3.97 & 0.88 \\
\hline
\end{tabular}

$\mathrm{P}$ value $<0.001$

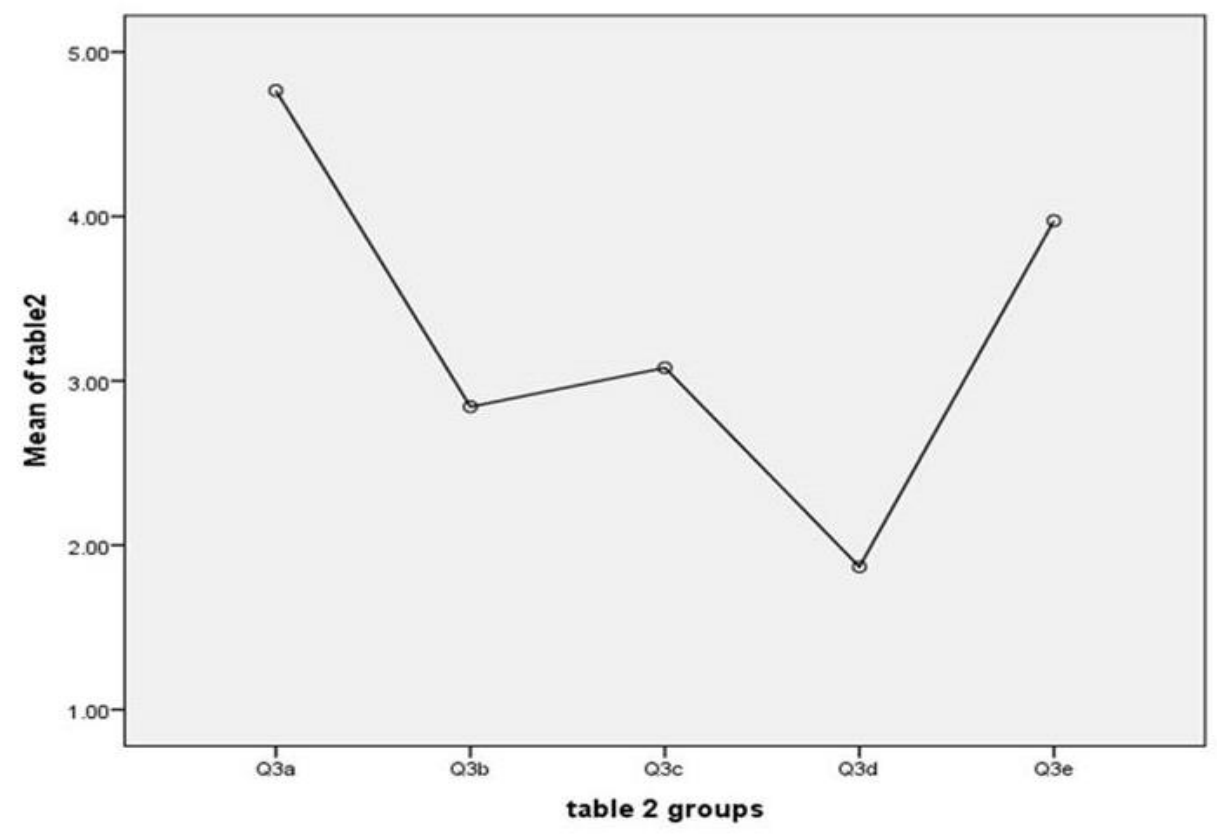

Fig 2 First batch feedback on different implemented modalities (Means Plots)

The open-ended question is about the most important concerns and suggestions for improvements. Eighty-nine students have answered this question and their responses are collected and presented in the discussion.

Also, the results of the focus group discussion are merged with that of the students' perception of the questionnaire.

\section{Discussion:}

One of the major medical education challenges in Egypt facing the switching from the traditional system to the Integrated Modular Curricula is that Faculties of medicine are used to the traditional system for decades (Peter et al., 1987). These challenges are not only due to the resistance of many of the educators to change, but also due to the habituation of most of the students to the pedagogical way of teaching that they have received in their highschools hindering their acknowledgement and understanding of the new system; an issue that needs great efforts and innovative approaches to be solved.

There are strenuous efforts from the decision-makers in the Supreme Council of Universities, and the Faculties' authorities and administrations regarding reforming the bylaws, continual training of the staff members in the field of medical education, and the orientation sessions for the students, together with regular follow up and regular assessment of the process. However, these efforts are trailing behind the development of futuristic curricula promoting changes towards a better quality of medical education.

CBL trains the students on how to solve medical cases and how to put a differential algorithm that eventually can lead to a proper diagnosis and management plan. It enhances the application of integrated knowledge and the establishment of multi-dimensional correlations. It also reinforces the analytic critical thinking and helps the learner to manage 
processes. Moreover, CBL allows solving clinical cases in a safe environment before the actual patient exposure during phase II of their academic course (Jill et al, 2012).

According to the collected responses from the two surveys used, $95.5 \%$ of the first batch (2016-2022) responded to the survey delivered by the pathology department reflecting a high degree of engagement and enthusiasm. This is to be compared with the response level to the survey delivered by the steering committee of the faculty (only $56.7 \%$ ).

According to the results, there is a significant satisfaction among the first batch (2016-2022) students regarding all the components of the pathology courses with the highest levels recorded concerning the CBL (mean of 4.77 \pm 0.46 ). The lowest level was $4.30 \pm 0.78$ for pathology assignments.

Comparing these results to the other applied modalities by comparing the CBL (4.77 \pm 0.46$)$ to the didactic lectures $(2.84 \pm 0.95)$, PBL $(3.08 \pm 1.19)$, PAL $(1.87 \pm 1.01)$, and the skill labs $(3.97 \pm 0.88)$ showed a statistically significant difference ( $\mathrm{p}$-values < 0.001$)$.

It is noticed that the least level of satisfaction was that of the PAL which appears contradictory to that reported by (Sumit et al 2017). This could be attributed to a defective implementation of this teaching modality.

In the traditional medical education systems, it is difficult to relate the basic science curricula to the clinical scenarios for phase I students (first three years of medical education) with very limited clinical exposure. This could be overcome by linking basic science material to case scenarios through the introduction of case-based learning (Minghong Bi et al., 2019).

As most of the students have been used to the teacher-centred learning in their high schools, we have found that andragogical implementation of the CBL has been greatly stressful for them. Thus, a gradual transition in the teaching methods through a pedagogical type of Enquiry-based instruction to andragogical self-directed learning has been decided. The four levels of guided Enquiry-based learning (EBL) are somewhat implemented in this model (Tim, 2009).

During the discussion in the CBL sessions, the smooth transition to a learner-centred model is achieved through this partly directed method, i.e. the instructor directs the students how to think of, then how to recreate similar scenarios, so it's not completely learnercentred.

We agree with Cindy et al. 2007 point of view regarding the EBL and PBL, where they claim that a heavily guided instruction leads to more constructivist and experiential learning outcomes.

This presented the primary scaffolding method in CBL teaching, which has reduced the cognitive load of structuring the complex tasks through directed instructional guidance. This method not only allowed the students to become gradually familiar with this type of learning but also they have become trained to inventing new case scenarios by themselves. They also developed soft skills like communication skills, collaboration, critical thinking, self-confidence, self-directed learning and creativity (Bereiter \& Scardamalia, 2006).

Applying mixed modalities CBL where lectures, tutorials, photo galleries, and CBL sessions are made available online for students before the discussion so that everyone can study what meets his learner style and at his own pace, with a mean level of satisfaction (4.46 \pm 0.72$)$ (Inge et al., 2007, Colin, 2012 and Athanasios et al., 2017). 
Also, presenting the mind map of the topic at the beginning of each session allows more integration and reasoning of the medical content (Martha and Karla, 2019). Moreover, the expected outcome of linking basic sciences as histology, anatomy, and physiology to the clinical setting is also fulfilled.

Two representatives of the students were selected as coauthors in this study based on the results of a scientific activities survey disseminated among the students (David, 2012). Both of them have shown the highest degree of interest.

Here we will present the students' perception and suggestions for improvements collected from the surveys and the focus group:

- After collecting student's feedback, most students have expressed that the old traditional methods of teaching which focused more on foundational concepts with limited clinical correlations, made studying harder and they could not memorize well and performed poorly in their examinations. However, after adding CBL modalities in the pathology course, they were able to better understand the pathophysiological mechanisms of the disease and to connect the clinical presentation with basic sciences they have learned, the learning process was also much more efficient as they have focused more on the overall picture, rather than individual components like microscopic pictures.

- CBL has also helped students to realize the significance of the information they absorb and will better make use of throughout their future clinical studies or medical careers. For instance, how to approach a case with a certain disease and what differential diagnosis they may suspect, what the most important lab tests to be done are, and coming up with the diagnosis and the proper management plan for the patient. This active thinking process performed by students with the supervision and guidance of the teaching staff will teach students the proper way of thinking about a medical case and provide them with the proper skills required to become better diagnosticians in the future.

These are just a few examples of the student's feedback concerning the implementation of the CBL learning technique in the pathology course. As this technique has also been used in conjunction with E-learning modality, students have been given the chance to witness a completely different experience that suits the wide array of student's preferences.

However, we truly suggest that CBL cases could be combined with audiovisuals and role plays for further engagement of the students in the teaching process and to be more appealing. Furthermore, CBL sessions could be combined along with the skills lab to recreate more realistic clinical scenarios that could be faced in the future during clinical practice. Mannequins and models can also be used to elaborate on these situations. Also recording the sessions may be used to serve as part of the learning aids to students, these videos are well-tailored to fit students' needs with due consideration to their national health demand rather than international videos.

\section{Conclusion:}

Reforming the medical curricula through the implementation of guided EBL modality in CBL followed by a smooth transition to the self-directed adult learning model is highly recommended in our community nowadays. This will be required until the high school education in Egypt undergoes the expected transition to adult, self-directed learning. Applying mixed modalities in CBL increases the students' satisfaction and enhances the transition to a self-directed learning model. 


\section{References:}

1. Athanasios Hassoulas, Elizabeth Forty, Mathew Hoskins, James Walters, and Stephen Riley. 2017. A case-based medical curriculum for the 21st century: The use of innovative approaches in designing and developing a case on mental health. Med Teach., 39:5, 505-51 https://doi.org/10.1080/0142159X.2017.1296564

2. Ambrose SA, Bridges MW, DiPietro M, Lovett MC, Norman MK.. 2010. How learning works: Seven research-based principles for smart teaching. How Does the Way Students Organize Knowledge Affect Their Learning? San Francisco, CA: Jossey-Bass. 40-65.

3. Bereiter C., Scardamalia M. 2006. Education for the knowledge age: Design-centred models of teaching and instruction. In P. A. Alexander \& P. H. Winne (Eds.), Handbook of educational psychology (2nd ed., 695-713). Mahwah, NJ: Erlbaum.

4. Cindy E. Hmelo-Silver, Ravit Golan Duncan, and Clark A. Chinn. 2007. Scaffolding and Achievement in Problem-Based and Inquiry Learning: A Response to Kirschner, Sweller, and Clark (2006). Educational Psychologist, 42: 2, 99-107. DOI: $10.1080 / 00461520701263368$

5. Chan YH. 2003: Biostatistics102: Quantitative Data - Parametric and Non-parametric Tests. Singapore Med J.; 44(8): 391-396.

6. Colin Mitchell. 2013. Wiki case-based learning for foundation doctors. Med Teach., 35: 5, 423, DOI: 10.3109/0142159X.2012.737061

7. David G. Brauer and Kristi J. Ferguson. 2015. The integrated curriculum in medical education: AMEE Guide No. 96; 37: 312-322. DOI: 10.3109/0142159X.2014.970998. Epub 2014 Oct 16.

8. David Leat and Anna Reid. 2012. Exploring the role of student researchers in the process of curriculum development. Curriculum Journal, 23: 2, 189-205. https://doi.org/10.1080/09585176.2012.678691

9. Dr. Inge Hege, Veronica Ropp, Martin Adler, Katja Radon, Gerald Mäsch, et al. 200 Experiences with different integration strategies of case-based e-learning. Med Teach., 29: 8, 791-797. https://doi.org/10.1080/01421590701589193

10. Ferguson KJ, Steiner LA, Kreiter CD, and Pomrehn PR. 1997. Assessment of case-based learning within a hybrid curriculum. Presentation at the Association of American Medical Colleges Research in Medical Education Annual Meeting, Washington, DC, 4 November 1997.

11. Ferguson KJ. 2006. Beyond multiple-choice questions: Using case-based learning patient questions to assess clinical reasoning. Med Educ; 40: 1142. https://doi.org/10.1111/j.13652929.2006.02592.x

12. Fostaty-Young S and Wilson RJ. 2000. Assessment and learning: The ICE approach. Winnipeg, MB: Portage and Main.

13. Jill Elizabeth Thistlethwaite, David Davies, Samilia Ekeocha, Jane M. Kidd, Colin MacDougall, et al. 2012. The effectiveness of case-based learning in health professional education. A BEME systematic review: BEME Guide No. 23.Med Teach., 34: 6, 421-444, Doi: 10.3109/0142159X.2012.680939.

14. Kaufman DM, Mann KV. 2010. Teaching and learning in medical education: How theory can inform practice. In: Swansick T, editor. Understanding medical education: Evidence, theory, and practice. West Sussex, UK: Wiley-Blackwell. 7-30.

15. Knowles MS. 1980. The modern practice of adult education: From pedagogy to andragogy. Chicago, IL: Follett.

16. Martha Peñuela-Epalza and Karla De la Hoz. 2019. Incorporation and evaluation of serial concept maps for vertical integration and clinical reasoning in case-based learning tutorials: Perspectives of students beginning clinical medicine. Med Teach., 41: 4, 1-8, DOI: 10.1080/0142159X.2018.1487046 
17. Mclean. 2016. Case-Based learning and its application in Medical and Health-care fields: a review of worldwide literature. Journal of Medical Education and Curricular Development . 3, 39-49, Doi:10.4137/JMecd.S20377.

18. Minghong Bi, Zhibiao Zhao, Jingru Yang, and Yaping Wang. 2019. Comparison of casebased learning and traditional method in teaching postgraduate students of medical oncology. Med Teach., 41:10, 1124-1128. https://doi.org/10.1080/0142159X.2019.1617414

19. NAQAAE 2017. National Academic Reference Standards (NARS) Medicine. 2nd edition.

20. National Research Council. 2000. How people learn. Brain, mind, experience, and school: Expanded edition. Washington, DC: The National Academies Press.

21. Peter L. Schwartz, Thomas M. Fiddes, and Alexander G. Dempster. 1987. The Case-based Learning Day: Introducing problem-based learning into a traditional medical curriculum. Med Teach., 9:3, 275-280. Published Online: 03 Jul 2009.

22. Sumit Grover, Neena Sood, and Anurag Chaudhary. 2017. Reforming Pathology Teaching in Medical College by Peer-assisted Learning and Student-oriented Interest Building Activities: A Pilot Study. Education for Health; 30:126-132. DOI: 10.4103/efh.EfH_267_16

23. Tabassum Naveed, Mazhar Bhatti, and Romana Malik. 2017. Perception of Medical Students Regarding Case-Based Learning, Journal of Rawalpindi Medical College (JRMC); 21(3): 303-305. https://www.journalrmc.com/index.php/JRMC/article/view/55

24. Thistlethwaite JE, Davies D, Ekeocha S, Kidd JM, MacDougall C, et al. 2012. The effectiveness of case-based learning in health professional education. A BEME systematic review. BEME guide number 23. Med Teach; 34:E421-E444. DOI: 10.3109/0142159X.2012.680939.

25. Tim Deignan. 2009. Enquiry-Based Learning: perspectives on practice. Teaching in Higher Education, 14:1, 13-28. https://doi.org/10.1080/13562510802602467

26. Twigg and Vani Veikoso. 2010. Teachers' practices, values, and beliefs for successful inquiry-based teaching in the International Baccalaureate Primary Years Programme. Journal of Research in International Education. 9 (1): 40-65. DOI: $10.1177 / 1475240909356947$.

\section{Take home messages:}

- Pathology can be the core of integration in our modular curricula.

- A smooth gradual transition from the pedagogical model to the andragogical model is recommended.

- Guided EBL approach to the CBL yields a high level of satisfaction.

- Mixed modalities CBL satisfies various learning styles.

- A customized CBL model yields superior results to the overtly andragogical PAL. 